Article

\title{
A Multi-Criteria Evaluation of the Urban Ecological Environment in Shanghai Based on Remote Sensing
}

\author{
Yuxiang Yan , Xianwen Yu *, Fengyang Long (D) and Yanfeng Dong \\ School of Transportation, Southeast University, Nanjing 211189, China; geodesic_y_yan@seu.edu.cn (Y.Y.); \\ fylong1990@seu.edu.cn (F.L.); yanfengdong@seu.edu.cn (Y.D.) \\ * Correspondence: yuxianwen@seu.edu.cn
}

Citation: Yan, Y.; Yu, X.; Long, F.; Dong, Y. A Multi-Criteria Evaluation of the Urban Ecological Environment in Shanghai Based on Remote Sensing. ISPRS Int. J. Geo-Inf. 2021, 10, 688 https://doi.org/10.3390/ijgi10100688

Academic Editors: Niko Lukač, Marko Bizjak and Wolfgang Kainz

Received: 1 September 2021

Accepted: 11 October 2021

Published: 13 October 2021

Publisher's Note: MDPI stays neutral with regard to jurisdictional claims in published maps and institutional affiliations.

Copyright: (c) 2021 by the authors. Licensee MDPI, Basel, Switzerland. This article is an open access article distributed under the terms and conditions of the Creative Commons Attribution (CC BY) license (https:// creativecommons.org/licenses/by/ $4.0 /)$.

\begin{abstract}
The urban ecological environment is related to human health and is one of the most concerned issues nowadays. Hence, it is essential to detect and then evaluate the urban ecological environment. However, the conventional manual detection methods have many limitations, such as the high cost of labor, time, and capital. The aim of this paper is to evaluate the urban ecological environment more conveniently and reasonably, thus this paper proposed an ecological environment evaluation method based on remote sensing and a projection pursuit model. Firstly, a series of criteria for the urban ecological environment in Shanghai City are obtained through remote sensing technology. Then, the ecological environment is comprehensively evaluated using the projection pursuit model. Lastly, the ecological environment changes of Shanghai City are analyzed. The results show that the average remote sensing ecological index of Shanghai in 2020 increased obviously compared with that in 2016. In addition, Jinshan District, Songjiang District, and Qingpu District have higher ecological environment quality, while Hongkou District, Jingan District, and Huangpu District have lower ecological environment quality. In addition, the ecological environment of all districts has a significant positive spatial autocorrelation. These findings suggest that the ecological environment of Shanghai has improved overall in the past five years. In addition, Hongkou District, Jingan District, and Huangpu District should put more effort into improving the ecological environment in future, and the improvement of ecological environment should consider the impact of surrounding districts. Moreover, the proposed weight setting method is more reasonable, and the proposed evaluation method is convenient and practical.
\end{abstract}

Keywords: ecological environment; remote sensing; projection pursuit; multi-criteria evaluation

\section{Introduction}

Urbanization is a worldwide trend and causes changes to the urban ecological environment. Currently, the urban ecological environment faces a series of problems, such as urban heat island effect, deforestation, and land degradation [1]. These problems have a connection with human health and may even induce life-threatening diseases [2]. The public has an urgent need to know the conditions of the urban ecological environment. Thus, it is crucial to detect and then evaluate the urban ecological environment.

The detection of ecological environment is carried out by manual investigation typically [3,4], which has many limitations. For example, it is unlikely to conduct the detection frequently on a large scale because of the high cost of labor, time, and capital [5]. In addition, the spatial resolution and temporal resolution are also low. As a result, the evaluation of ecological environment lacks convenience. However, the remote sensing (RS) is an advanced means of detecting the ecological environment [6]. Through remote sensing technology, the imagery of Earth's surface is obtained from satellite sensors. The satellite imagery provides multispectral information for estimating ecological criteria, such as the normalized difference vegetation index (NDVI) [6,7] and land surface temperature (LST) $[8,9]$. A major advantage of remote sensing is that it can be used to automatically detect 
the ecological environment, saving time and effort. The remote sensing method has several practical applications. Qureshi et al. [5] modeled the ecological conditions in wetland by means of remote sensing. Yue et al. [7] studied the ecological changes in 35 cities using remote sensing. Zhu et al. [10] monitored the ecological effects of open pits in mining areas using remote sensing. Bi et al. [11] studied the ecological environment in an arid region according to remote sensing data. The above studies have proved the feasibility and practicability of detecting ecological environment by remote sensing. Some researchers evaluate the ecological environment according to a single criterion. Zhang et al. [12] concentrated on evaluating the change of natural ecological land through the land use data. Jiang et al. [9] focused on the land surface temperature (LST) retrieving according to remote sensing data. Peng et al. [13] focused on studying the urban heat island effect through anthropogenic heat flux. However, the evaluation of ecological environment based on a single criterion is biased and lacks comprehensiveness. There are some studies that evaluate the ecological environment according to a number of criteria. Zhang et al. [1] assessed the urban ecoenvironment quality through greenness, moisture, dryness, and heat. Firozjaei et al. [14] modeled the land surface ecological status by biophysical composition index (BCI) information, land surface temperature (LST), and remote sensing-based ecological index (RSEI). Hu et al. [15] assessed the urban ecological quality by integrating the primary land surface components and the climate using the pressure-state-response framework. In these studies, the ecological environment monitored by remote sensing satellites contains a number of criteria. How to make a comprehensive evaluation of these criteria is a problem we need to study. Mathematically speaking, this is a multi-criteria evaluation problem, and some efforts have been made to solve this one. The principal component analysis (PCA) is most commonly used, and a lot of researchers also adopt this method for integrating remote sensing ecological criteria [10,15-17]. For example, Xu et al. [6] studied the combination of different ecological criteria using the principal component analysis (PCA). There are also many studies using other methods. Yue et al. [7] adopted the analytic hierarchy process (AHP) to integrate ecological criteria. Liu et al. [18] developed a visibility graph power geometric aggregation operator for integration. Liao et al. [19] proposed a comprehensive evaluation model based on knowledge granulation entropy. Wang et al. [20] adopted the analytic hierarchy process (AHP) and the technique for order preference by similarity to an ideal solution (TOPSIS) Method. However, the methods proposed by previous studies are somewhat complicated in practical operation. For instance, there still exists an unclear issue about how many components to select in the PCA method. In addition, previous research gives one ecological criterion to different weights at different times and neglects the importance of consistency in weighting.

With the purpose of dealing with the inadequacies of previous studies, this paper proposed a remote sensing ecological environment evaluation method based on the projection pursuit model. Firstly, a series of ecological criteria for the urban ecological environment are obtained through remote sensing technology. Then, the ecological environment is comprehensively evaluated using the projection pursuit model, which is a convenient multi-criteria evaluation method. In addition, this paper handles remote sensing ecological data as a whole, and once the weight of each ecological criterion is given, it remains fixed. Lastly, the ecological environment changes of Shanghai City in the past five years are analyzed based on the evaluation results. The main contributions of our work are that the weight setting method is more reasonable and the proposed method is more convenient; thus, the analysis is more meaningful.

The remaining part of this paper is organized in the following way: Section 2 explains the processing methods; Section 4 explains the remote sensing data; Section 5 presents the results of ecological environment evaluation; Section 6 discusses the findings. Lastly, the conclusions are given. 


\section{Methods}

Remote sensing is a technology that uses satellite sensors to perform non-contact measurements of Earth's surface [21]. Radiations emitted or reflected from Earth's surface are detected by satellite sensors, and then we can process and analyze the radiation information.

\subsection{Ecological Criteria}

The remote sensing based ecological index (RSEI) was proposed by Xu [22]. Four ecological criteria closely related to human activities were selected as the evaluation indicators of urban ecological environment, namely greenness, wetness, dryness, and heat. The RSEI has an advantage that it is convenient to use based on satellite remote sensing technology and is widely used in the evaluation of urban ecological environment currently $[1,5,6]$. The description of ecological criteria is shown in Table 1 . The RSEI is calculated as follows:

$$
\text { RSEI }=f(\text { Greenness, Wetness, Dryness, Heat })
$$

Table 1. Ecological criteria.

\begin{tabular}{lclll}
\hline Criterion & Indicator & Description & Type & Reference \\
\hline Greenness & NDVI & Vegetation cover & The larger the better & {$[5,6]$} \\
Wetness & Wetness & Moisture of soil and plants & The larger the better & {$[5,6]$} \\
Dryness & NDBSI & Buildings and bare soil & The smaller the better & {$[5,6]$} \\
Heat & LST & Land surface temperature & The smaller the better & {$[5,6]$} \\
\hline
\end{tabular}

Figure 1 shows a schematic view of detecting ecological criteria by remote sensing.

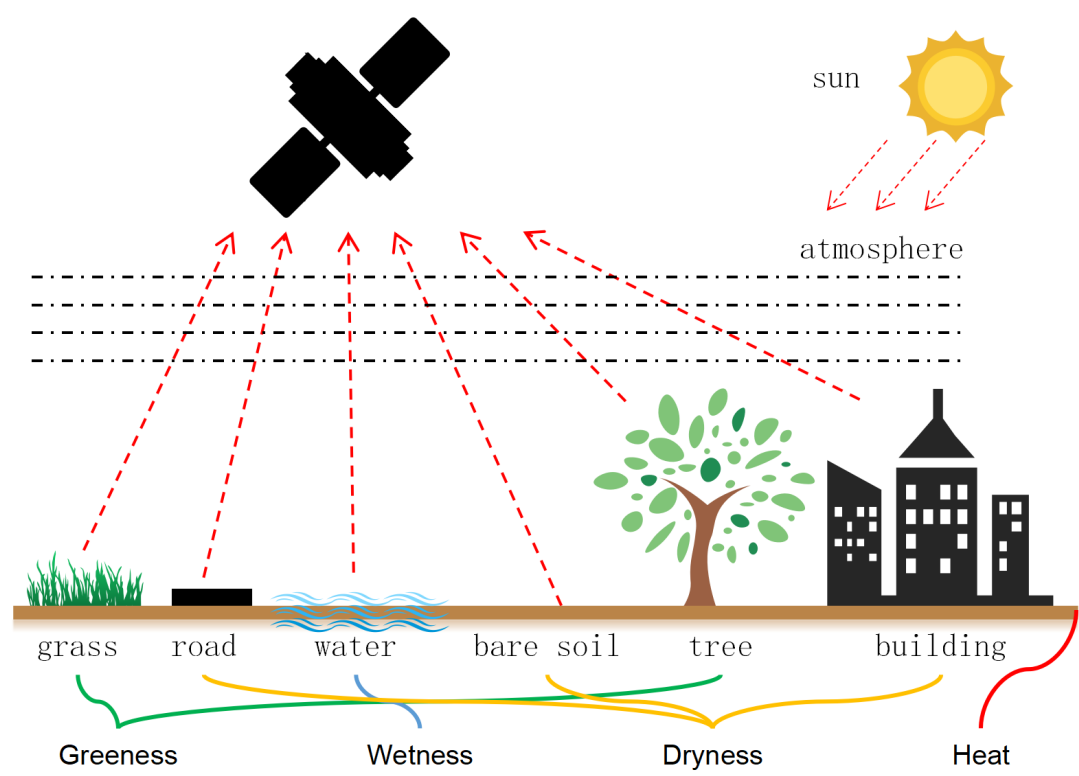

Figure 1. Schematic view of remote sensing.

It can be seen from Figure 1 that these ecological criteria are easily obtained through remote sensing technology. The detailed meaning of these ecological criteria is explained as follows.

\section{(1) Greenness;}

The Greenness [6] reflects the vegetation cover, and the higher the greenness, the better the ecological environment. The normalized difference vegetation index (NDVI) [5] is often 
used to measure vegetation cover in remote sensing. Therefore, this paper uses NDVI to characterize the greenness. The formula for calculating NDVI is as follows:

$$
N D V I=\frac{\rho_{N I R}-\rho_{\text {Red }}}{\rho_{N I R}+\rho_{\text {Red }}}
$$

where $\rho_{N I R}$ and $\rho_{\text {Red }}$ denote reflectance of the near-infrared band and the red band, respectively.

(2) Wetness;

The Wetness [6] reflects the moisture of soil and plants, and the higher the wetness, the better the ecological environment. The formula for calculating wetness through Sentinel-2A image [23] is given by:

$$
\text { Wetness }=0.1509 \rho_{2}+0.1973 \rho_{3}+0.3279 \rho_{4}+0.3406 \rho_{8}-0.7112 \rho_{11}-0.4572 \rho_{12}
$$

where $\rho_{i}$ represents the reflectance of corresponding band in Sentinel-2A image, and $i=2,3,4,8,11,12$.

(3) Dryness;

The Dryness [6] reflects the soil drying, and the smaller the dryness, the better the ecological environment. The dryness indicator called NDBSI is a combination of built-up index (BI) and bare soil index (SI). The formula for calculating NDBSI through Sentinel-2A image [23] is given below:

$$
N D B S I=\frac{S I+B I}{2}
$$

where

$$
\begin{aligned}
& S I=\frac{\left(\rho_{11}+\rho_{4}\right)-\left(\rho_{8}+\rho_{2}\right)}{\left(\rho_{11}+\rho_{4}\right)+\left(\rho_{8}+\rho_{2}\right)} \\
& B I=\frac{\frac{2 \rho_{11}}{\rho_{11}+\rho_{8}}-\left(\frac{\rho_{8}}{\rho_{8}+\rho_{4}}+\frac{\rho_{3}}{\rho_{3}+\rho_{11}}\right)}{\frac{2 \rho_{11}}{\rho_{11}+\rho_{8}}+\left(\frac{\rho_{8}}{\rho_{8}+\rho_{4}}+\frac{\rho_{3}}{\rho_{3}+\rho_{11}}\right)}
\end{aligned}
$$

where $\rho_{i}$ represents the reflectance of corresponding band in Sentinel-2A image, and $i=2,3,4,8,11$.

\section{(4) Heat}

The Heat [6] reflects the land surface temperature related to urban thermal island effect, and the smaller the heat, the better the ecological environment. The formula for obtaining land surface temperature by means of remote sensing is derived below.

According to the Planck's law, the land surface temperature $T_{s}[24]$ can be expressed as:

$$
T_{S}=\frac{K_{2}}{\ln \left(\frac{K_{1}}{B}+1\right)}
$$

where $B$ is the black body spectral radiance at temperature $T_{s} . K_{1}$ and $K_{2}$ are constants.

However, the $B$ can be calculated by means of the Radiative Transfer Equation. Figure 2 shows an illustration of the Radiative Transfer Equation.

According to Figure 2 , the Radiative Transfer Equation [24] can be written as:

$$
L_{\lambda}=\tau\left[\varepsilon B+(1-\varepsilon) L_{\downarrow}\right]+L_{\uparrow}
$$

where $L_{\lambda}$ is the total radiance received by the satellite, $L_{\uparrow}$ is upwelling radiance, $L_{\downarrow}$ is downwelling radiance, and $\varepsilon$ is emissivity and $\tau$ is atmospheric transmission. 


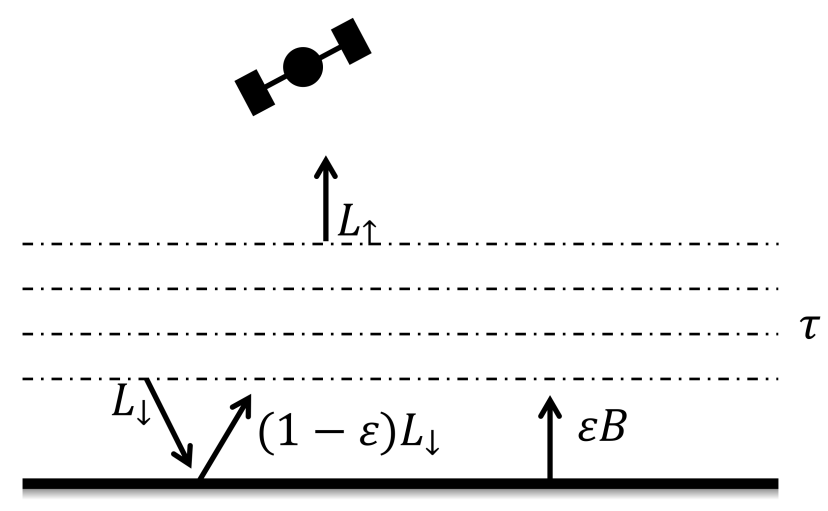

Figure 2. Schematic view of the Radiative Transfer Equation.

Equation (8) can be rewritten as:

$$
B=\frac{L_{\lambda}-L_{\uparrow}-\tau(1-\varepsilon) L_{\downarrow}}{\tau \varepsilon}
$$

By substituting Equation (9) into Equation (7), we get:

$$
T_{S}=\frac{K_{2}}{\ln \left(\frac{K_{1} \tau \varepsilon}{L_{\lambda}-L_{\uparrow}-\tau(1-\varepsilon) L_{\downarrow}}+1\right)}
$$

The unit of $T_{s}$ in Equation (10) is Kelvin, which can be converted to Celsius as follows:

$$
T_{S}\left[{ }^{\circ} \mathrm{C}\right]=T_{S}-273.15=\frac{K_{2}}{\ln \left(\frac{K_{1} \tau \varepsilon}{L_{\lambda}-L_{\uparrow}-\tau(1-\varepsilon) L_{\downarrow}}+1\right)}-273.15
$$

where $T_{\mathcal{S}}\left[{ }^{\circ} \mathrm{C}\right]$ denotes the land surface temperature in Celsius.

\subsection{Multi-Criteria Evaluation Model}

The ecological environment monitored by remote sensing satellites contains a number of criteria. Making a comprehensive evaluation of these criteria belongs to a multi-criteria evaluation problem. In the multi-criteria evaluation problem, each sample to be evaluated is composed of $n$ criteria. Then, each sample can be regarded as a point in the $\mathbb{R}^{n}$ linear space. The basic idea of projection pursuit model is to project these points onto an appropriate direction vector [25-27]. Figure 3 shows the process, and each step is described in detail below. 


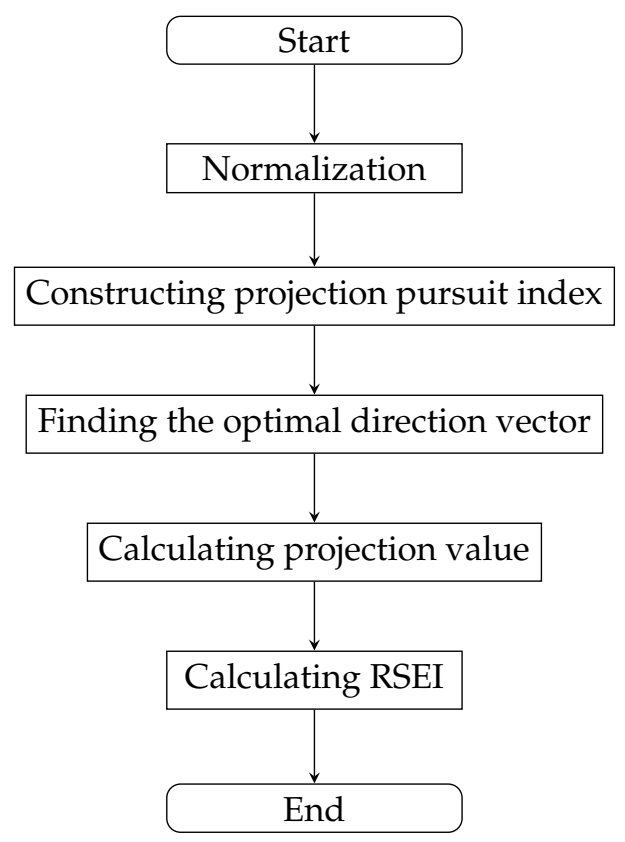

Figure 3. Flow chart of projection pursuit model of calculating RSEI.

Step 1: Normalization.

In order to eliminate the influence caused by different criteria units, each criterion variable needs to be normalized. Define $\left\{x_{1}, x_{2}, \ldots, x_{m}\right\}$ as a real number sequence composed of the values of all samples corresponding to a certain criterion. The normalization method is introduced below [26-28].

(1) When the larger the criterion, the better the ecological environment:

$$
r_{i}=\frac{x_{i}-x_{\min }}{x_{\max }-x_{\min }}
$$

where $i \in\{1,2, \ldots, m\}, x_{\min }=\min \left\{x_{1}, x_{2}, \ldots, x_{m}\right\}, x_{\max }=\max \left\{x_{1}, x_{2}, \ldots, x_{m}\right\}, r_{i}$ is the value of $j$-th sample corresponding to a certain criterion after normalization.

(2) When the smaller the criterion, the better the ecological environment:

$$
r_{i}=1-\frac{x_{i}-x_{\min }}{x_{\max }-x_{\min }}
$$

in the usual notation.

Step 2: Constructing projection pursuit index.

Let $\boldsymbol{a}=\left(a_{1}, a_{2}, \ldots, a_{n}\right)$ be a unit direction vector, and let $\boldsymbol{y}^{(i)}=\left(y_{1}^{(i)}, y_{2}^{(i)}, \ldots, y_{n}^{(i)}\right)$ be a vector composed of the values of all criteria corresponding to a certain sample. Then, the scalar projection $z^{(i)}$ of $\boldsymbol{y}^{(i)}$ onto $\boldsymbol{a}$ is given by:

$$
z^{(i)}=\left\langle\boldsymbol{y}^{(i)}, \boldsymbol{a}\right\rangle=\sum_{j=1}^{n} y_{j}^{(i)} a_{j}
$$

where $\langle\cdot\rangle$ denotes inner product.

Let $\left\{\boldsymbol{y}^{(1)}, \boldsymbol{y}^{(2)}, \ldots, \boldsymbol{y}^{(m)}\right\}$ be a vector sequence composed of $m$ samples, and let $\left\{z^{(1)}, z^{(2)}\right.$, $\left.\ldots, z^{(m)}\right\}$ be a real number sequence formed by the projection of $\boldsymbol{y}^{(i)}$ onto $\boldsymbol{a}, i=1,2, \ldots, m$. Define the projection pursuit index function $Q(\boldsymbol{a})$ as follows [25-27]:

$$
Q(a)=S \cdot D
$$

where 
$S \quad=\operatorname{std}\left(\left\{z^{(1)}, z^{(2)}, \ldots, z^{(m)}\right\}\right)$, in other words, the standard deviation of the sequence $\left\{z^{(1)}, z^{(2)}, \ldots, z^{(m)}\right\}$;

$D=\sum_{i=1}^{m} \sum_{j=1}^{m}\left(R-r_{i j}\right) u\left(R-r_{i j}\right)$, represents local density;

$r_{i j}=\left|z^{(i)}-z^{(j)}\right|, i \in\{1,2, \ldots, m\}, j \in\{1,2, \ldots, m\}$, represents the distance between samples;

$R=r_{\max }+\frac{n}{2}$, represents the window radius of local density [29];

$r_{\max }=\max \left\{r_{i j}\right\}$;

$u(x)=\left\{\begin{array}{l}1, x \geq 0 \\ 0, x \leq 0\end{array}\right.$, denotes the step function.

Step 3: Finding the optimal direction vector.

Finding the optimal direction vector $\boldsymbol{a}$ by maximizing $\mathrm{Q}(\mathrm{a})$ :

$$
\begin{aligned}
& \max Q(\boldsymbol{a}) \\
& \text { subject to: }\|\boldsymbol{a}\|=1 \text { and } a_{i} \in[0,1]
\end{aligned}
$$

where $\|\cdot\|$ denotes the length of a vector, $i \in\{1,2, \ldots, n\}$.

This is a nonlinear optimization problem, and there are many ways to solve such a problem. For example, swarm intelligence algorithms have been used to find the optimal solution $[26,27]$.

Step 4: Calculating projection value.

Once the optimal direction vector $\hat{a}$ is obtained, the optimal projection value sequence $\left\{\hat{z}^{(1)}, \hat{z}^{(2)}, \ldots, \hat{z}^{(m)}\right\}$ can be acquired according to Equation (14).

Step 5: Calculating RSEI.

Let $\hat{z}_{\min }=\min \left\{\hat{z}^{(1)}, \hat{z}^{(2)}, \ldots, \hat{z}^{(m)}\right\}$ and $\hat{z}_{\max }=\max \left\{\hat{z}^{(1)}, \hat{z}^{(2)}, \ldots, \hat{z}^{(m)}\right\}$. Then, the RSEI is defined as

$$
R S E I^{(i)}=\frac{\hat{z}^{(i)}-\hat{z}_{\min }}{\hat{z}_{\max }-\hat{z}_{\min }}
$$

where $i \in\{1,2, \ldots, m\}$.

Subsequently, a comprehensive evaluation analysis can be performed based on the RSEI values, and a larger RSEI value means a better ecological environment quality.

\subsection{Spatial Autocorrelation}

This study also conducted an analysis of spatial autocorrelation, and the analysis involves a spatial weights matrix. Contiguity weights matrix [30,31] is a classic one and composed of three types, namely Rook, Bishop, and Queen, which can be seen in Figure 4. Rook contiguity means that the matrix element $w_{i j}=1$ if two cities share a common border, and $w_{i j}=0$ if not. Bishop contiguity means that the matrix element $w_{i j}=1$ if two cities share a common vertex, and $w_{i j}=0$ if not. Queen contiguity means that the matrix element $w_{i j}=1$ if two cities share a common border or vertex, and $w_{i j}=0$ if not. In this study, the spatial weights matrix is set to a row-normalized Queen contiguity weights matrix.

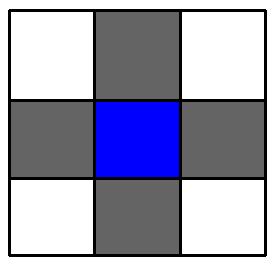

Rook

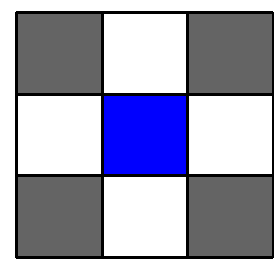

Bishop

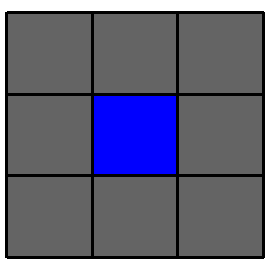

Queen

Figure 4. Spatial contiguity matrix. 
The Moran's I statistic [30] for RSEI can be written as:

$$
\begin{aligned}
M_{R S E I} & =\frac{\sum_{i=1}^{15} \sum_{j=1}^{15}\left(R S E I_{i}-\overline{R S E I}\right) w_{i j}\left(R S E I_{j}-\overline{R S E I}\right) / 15}{\sum_{i=1}^{15}\left(R S E I_{i}-\overline{R S E I}\right)^{2} / 15} \\
& =\frac{\sum_{i=1}^{15} \sum_{j=1}^{15}\left(R S E I_{i}-\overline{R S E I}\right) w_{i j}\left(R S E I_{j}-R \overline{S E I}\right)}{\sum_{i=1}^{15}\left(R S E I_{i}-\overline{R S E I}\right)^{2}}
\end{aligned}
$$

where $\overline{R S E I}=\left(\sum_{i=1}^{15} R S E I_{i}\right) / 15, w_{i j}$ is the entry of a row-standardized Queen contiguity weights matrix.

\subsection{Technical Route}

The process of calculating RSEI from remote sensing images is shown in Figure 5, and it can be seen that the process consists mainly of the following steps.

1. Acquiring remote sensing images of the relevant study area.

2. Data preprocessing, such as layer stacking, radiometric calibration, making a subset, etc.

3. Based on the methods in Section 2.1, the remote sensing images are processed to obtain the four ecological criteria.

4. The zonal statistics are conducted to obtain the average values of ecological criteria in each district.

5. The projection pursuit model is used to comprehensively evaluate the four ecological criteria, and the RSEI is obtained.

6. Analyzing the RSEI results.

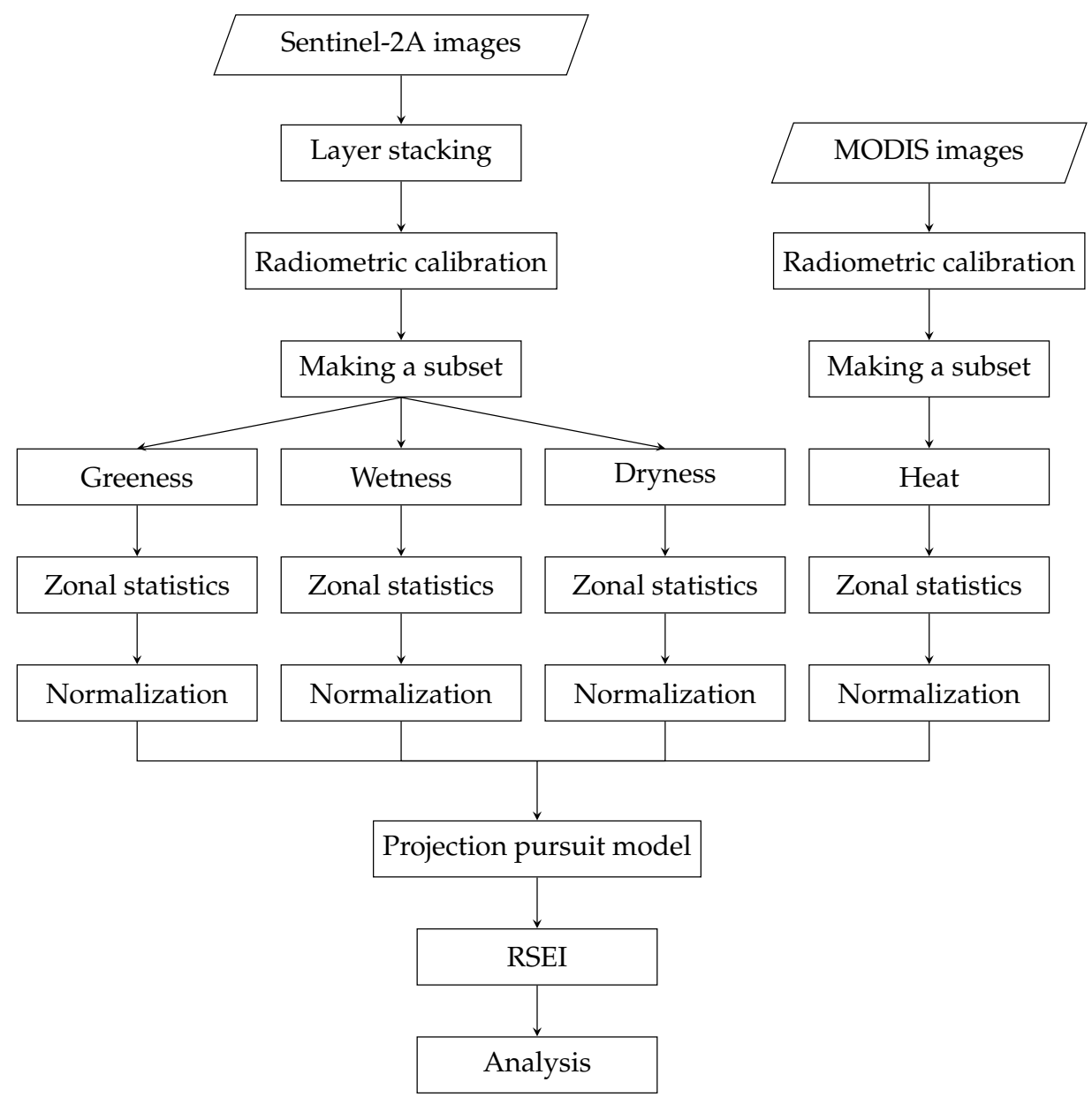

Figure 5. Technical route. 


\section{Study Area}

This research studied the ecological environment of 15 districts in Shanghai. Shanghai is located in the east coast of China, adjacent to Jiangsu and Zhejiang provinces. The longitude range is $120^{\circ} 52^{\prime} \mathrm{E} \sim 122^{\circ} 12^{\prime} \mathrm{E}$, and the latitude range is $30^{\circ} 40^{\prime} \mathrm{N} \sim 31^{\circ} 53^{\prime} \mathrm{N}$. Shanghai has a subtropical monsoon climate, with an annual average temperature of about $17^{\circ} \mathrm{C}$ and a land area of about $6340.5 \mathrm{~km}^{2}$ [32]. There are many enterprises in Shanghai, and the business is highly developed. It is an important economically developed area in China, and the gross regional product in 2020 is about $3870 \times 10^{9}$ Yuan [32]. Figure 6 shows the map of study area.

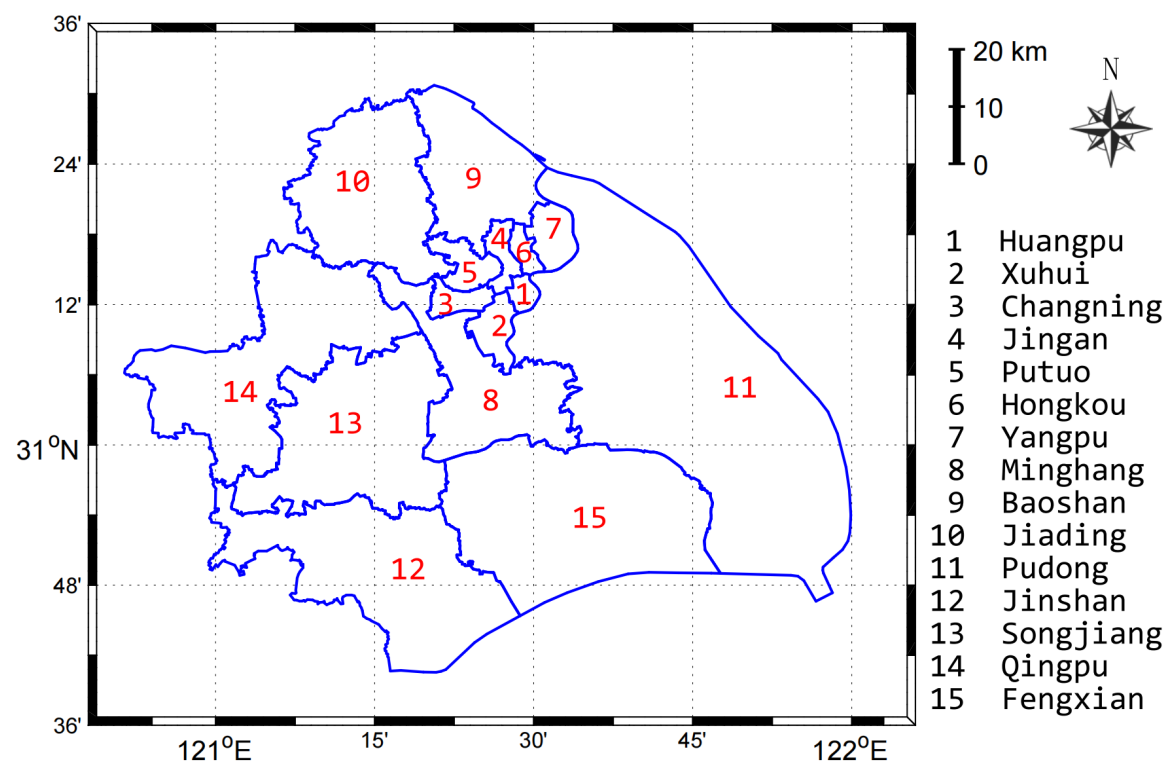

Figure 6. Study area.

Shanghai governs 16 districts, and Figure 6 shows that this paper just studied 15 of them. The reason why Chongming District is not included in this study is that Chongming District is an outlying island and has inconvenient land transportation with surrounding districts.

\section{Data}

\subsection{Data Sources}

The remote sensing images of Sentinel-2A and MODIS were used in this work, and the information about Sentinel-2A and MODIS is available on https://scihub.copernicus.eu/, accessed on 8 May 2021 and https: / /ladsweb.modaps.eosdis.nasa.gov/ accessed on 8 May 2021. The Sentinel-2 contains two satellites, Sentinel-2A and Sentinel-2B, which can obtain high-resolution multispectral satellite images. The number of spectral bands in Sentinel-2A satellite is 13, including visible band, near infrared band, short wave infrared band, etc. There are three kinds of spatial resolutions, namely $10 \mathrm{~m}, 20 \mathrm{~m}$, and $60 \mathrm{~m}$. Table 2 shows a part of band information on the Sentinel-2A satellite. MODIS (Moderate Resolution Imaging Spectroradiometer) is a radiometer carried by the Terra and Aqua satellites which are synchronized with the sun. There are 36 spectral bands in MODIS, and the MOD11A2, which is a product of MODIS, provides a spatial resolution of one kilometer for land surface temperature and emissivity. MODIS products are suitable for the research of ecological environment, climate, land, etc.

Table 3 shows the basic information about raw data we used in this paper. The sensing dates of Sentinel-2A images are 23 July 2016, 18 July 2017, 23 July 2018, 18 July 2019, and 22 July 2020, respectively, and the sensing dates of MODIS images are almost the same. The DOY (day of year) of these remote sensing images are similar, and observing the ecological environment changes on the similar DOY every year makes the experiment results more convincing. The Sentinel-2A images are downloaded from https://scihub.copernicus.eu/ 
accessed on 8 May 2021, and the MODIS images are available on https:/ /ladsweb.modaps. eosdis.nasa.gov/ accessed on 8 May 2021. Some software (e.g., ENVI, Geoda, MATLAB, QGIS) is also used in this experiment.

Table 2. The partial band information on Sentinel-2A.

\begin{tabular}{ccccc}
\hline Band & $\begin{array}{c}\text { Central Wavelength } \\
(\mathbf{n m})\end{array}$ & $\begin{array}{c}\text { Bandwidth } \\
(\mathbf{n m})\end{array}$ & $\begin{array}{c}\text { Spatial Resolution } \\
(\mathbf{m})\end{array}$ & Description \\
\hline 2 & 492.4 & 66 & 10 & Blue \\
3 & 559.8 & 36 & 10 & Green \\
4 & 664.6 & 31 & 10 & Red \\
8 & 832.8 & 106 & 10 & Near infrared \\
11 & 1613.7 & 91 & 20 & Short wave infrared \\
12 & 2202.4 & 175 & 20 & Short wave infrared \\
\hline
\end{tabular}

Table 3. The information on raw data.

\begin{tabular}{ccccc}
\hline Sensor & Product & Tile Number & Temporal Resolution & Sensing Date \\
\hline \multirow{3}{*}{ Sentinel-2A } & S2A_MSIL1C & T51RUQ & & 23 July 2016 \\
& & & 18 July 2017 & 23 July 2018 \\
& & & 18 July 2019 \\
& & & 22 July 2020 \\
\hline \multirow{2}{*}{ MODIS } & MOD11A2 & H28V5 & & 19 July 2016-26 July 2016 \\
& & & & 20 July 2017-27 July 2018 \\
& & & & 20 July 2018-27 July 2018 \\
& & & 20 July 2019-20 July 2019 \\
& & & 19 July 2020-26 July 2020 \\
\hline
\end{tabular}

\subsection{Data Preprocessing}

The raw images must be preprocessed, such as layer stacking, making a subset and radiometric calibration. Layer stacking is to combine different band images into a multiband file, which is convenient for subsequent band mathematical operation [6,21]. Making a subset refers to selecting a smaller image only containing the study area according to Figure 6. Radiometric calibration is to convert the DN (digital number) value into radiance, reflectance, etc.

The formula for radiometric calibration [33] is as follows:

$$
y=G \times D+b
$$

where $G$ denotes gain parameter, $D$ denotes digital number $(\mathrm{DN})$ value, $b$ denotes bias parameter, and $y$ is the reflectance or radiance after calibration.

For the S2A_MSIL1C image product of Sentinel-2A, we can know that the gain parameter is 0.0001 , and the bias parameter is 0 according to ENVI software. Therefore, the formula for converting the DN value into reflectance is as follows:

$$
r=0.0001 \times D
$$

where $r$ denotes reflectance, and $D$ denotes the digital number $(\mathrm{DN})$ value.

For the MOD11A2 image product of MODIS, we can know that the gain parameter is 0.02 according to ENVI software, and the unit of land surface temperature is Kelvin. Therefore, the formula for converting DN value into land surface temperature in Celsius is as follows:

$$
\begin{aligned}
T_{\mathcal{S}}\left[{ }^{\circ} \mathrm{C}\right] & =T_{\mathcal{S}}[\mathrm{K}]-273.15 \\
& =0.02 \times D-273.15
\end{aligned}
$$


where $T_{s}\left[{ }^{\circ} \mathrm{C}\right]$ denotes the land surface temperature in Celsius, $T_{S}[\mathrm{~K}]$ denotes the land surface temperature in Kelvin, and $D$ denotes the digital number (DN) value.

\section{Results}

\subsection{Raw Ecological Criteria}

The ecological criteria can be obtained by remote sensing image processing according to the methods in Section 2.1. The Greenness, Wetness, and Dryness can be calculated using the reflectance images of Sentinel-2A, and the Heat can be acquired from the MODIS MOD11A2 product. Figures 7-10 display the results of Greenness, Wetness, Dryness, and Heat, respectively. When calculating the ecological criteria using the reflectance images of Sentinel-2A, a threshold was also set for smoothing, and the results are rounded to three decimal places.
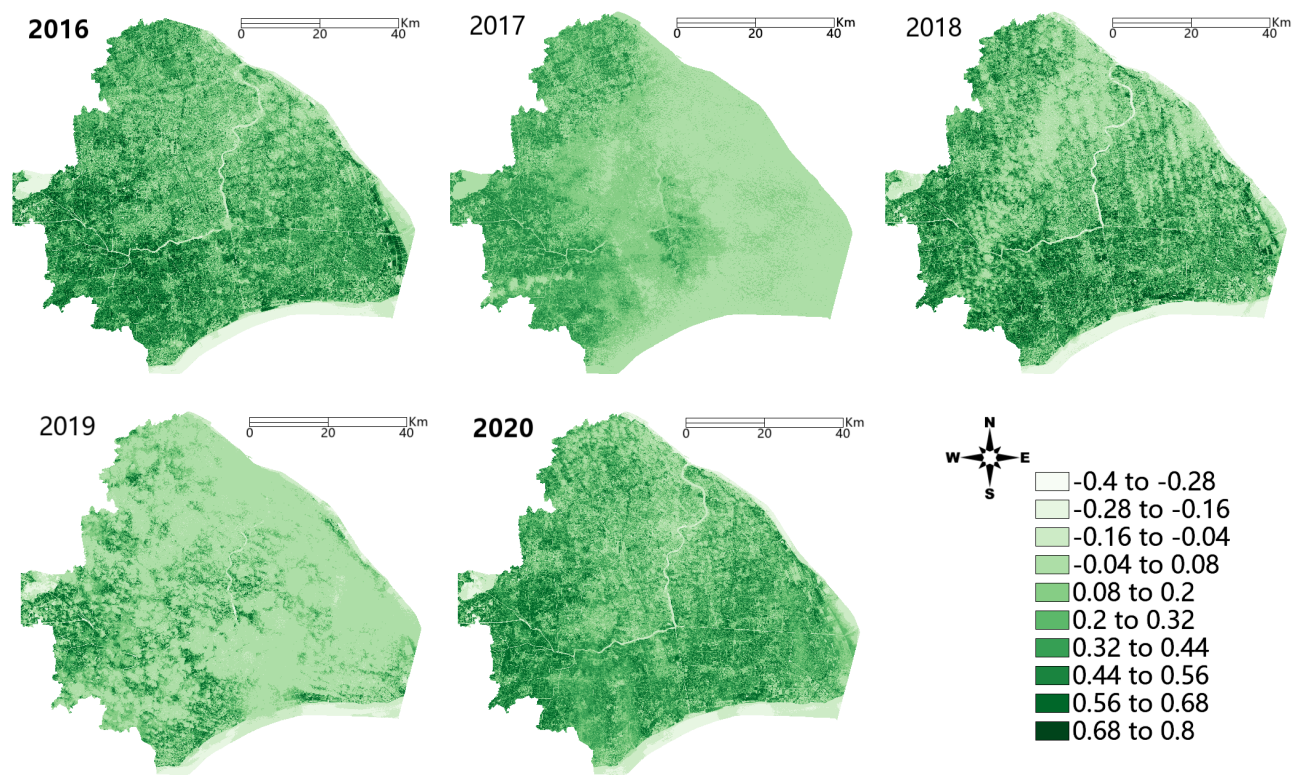

Figure 7. Greenness.
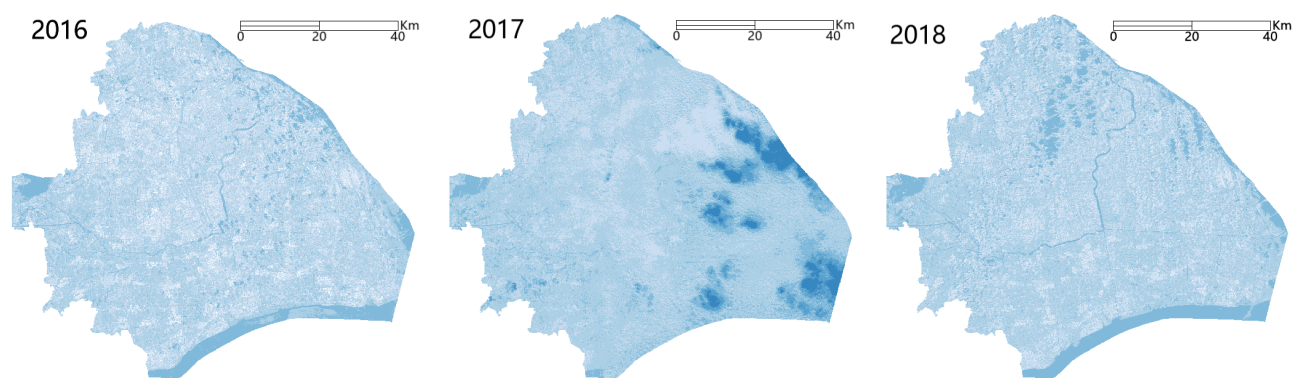

Figure 8. Cont. 

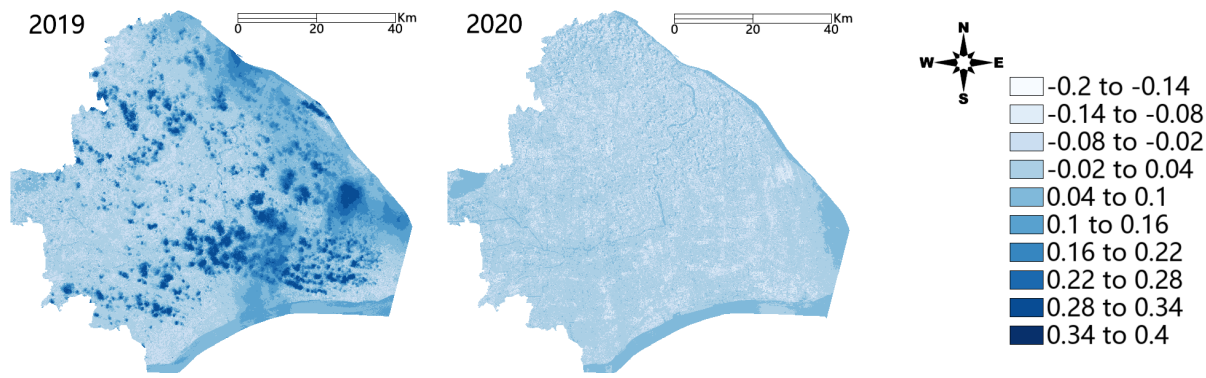

Figure 8. Wetness.
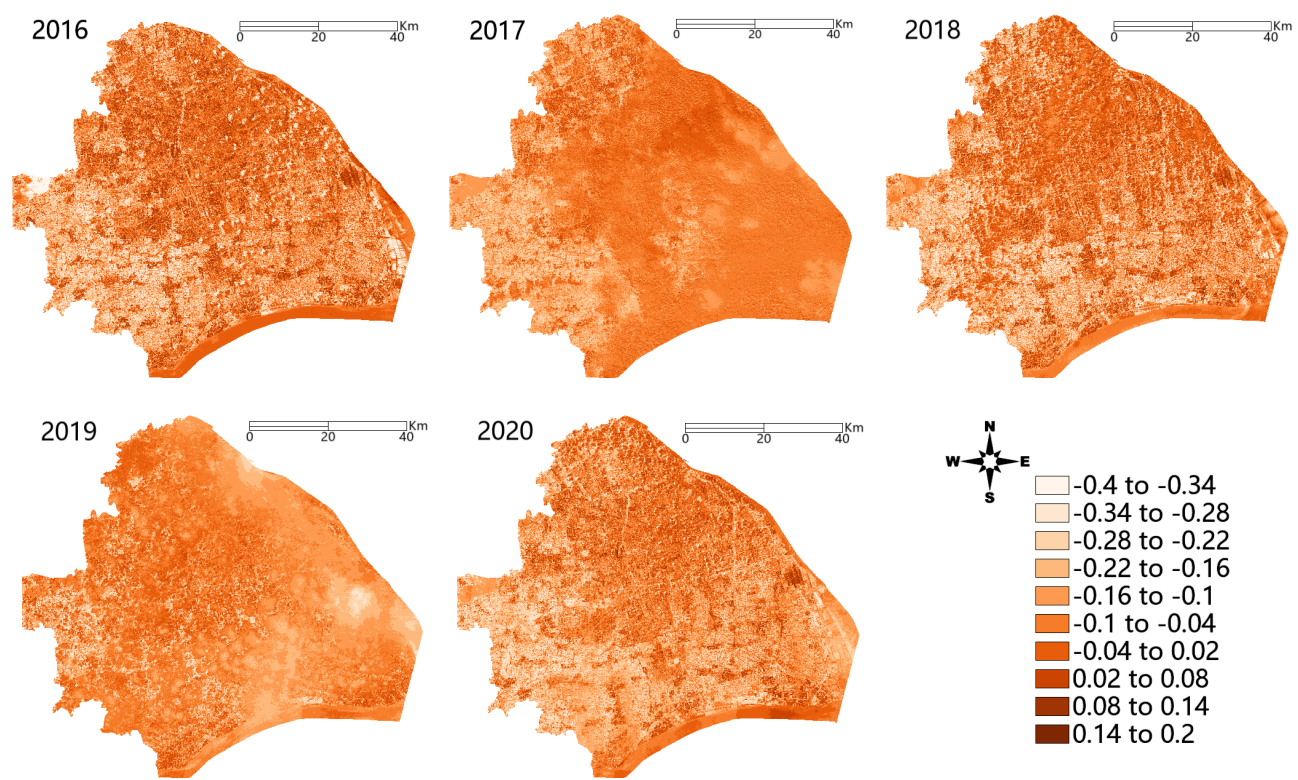

-0.4 to -0.34

-0.34 to -0.28 -0.28 to -0.22 $\square-0.22$ to -0.16

-0.16 to -0.1

-0.1 to -0.04

-0.04 to 0.02

0.02 to 0.08

0.08 to 0.14

Figure 9. Dryness.
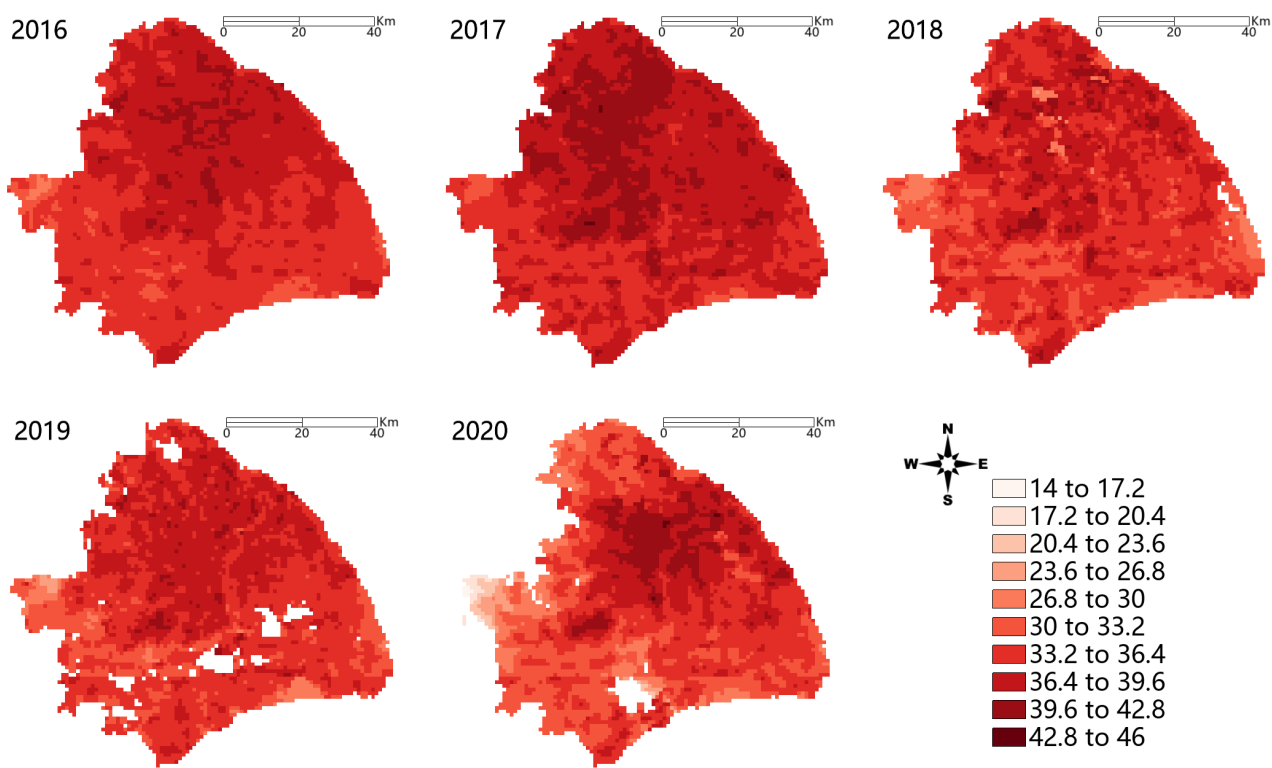

Figure 10. Heat. 


\subsection{Zonal Statistics}

This study is to evaluate and analyze the ecological environment of 15 districts in Shanghai, and so it is necessary to obtain the average values of ecological criteria in each district. The zonal statistics are conducted, and Figures 11-14 present the average values of Greenness, Wetness, Dryness, and Heat, respectively, in each district.
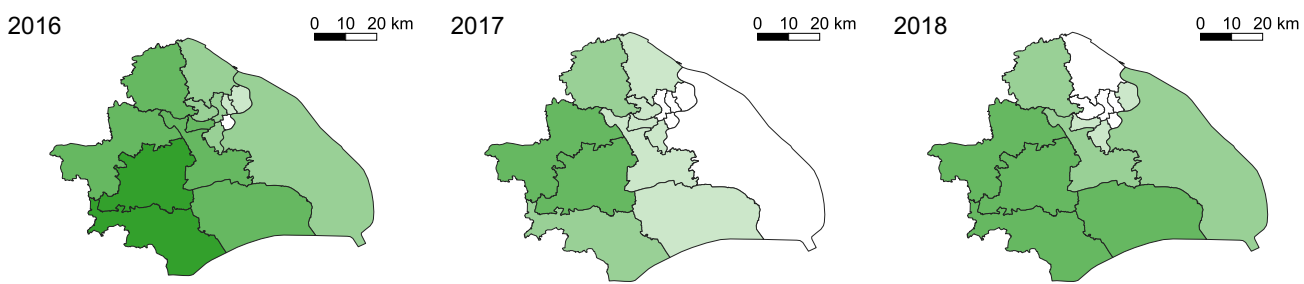

2019

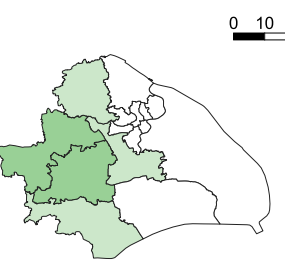

$0 \quad 10 \quad 20 \mathrm{~km}$
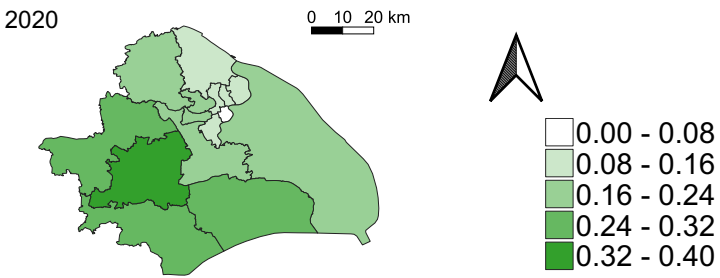

Figure 11. Average value of Greenness in each district.
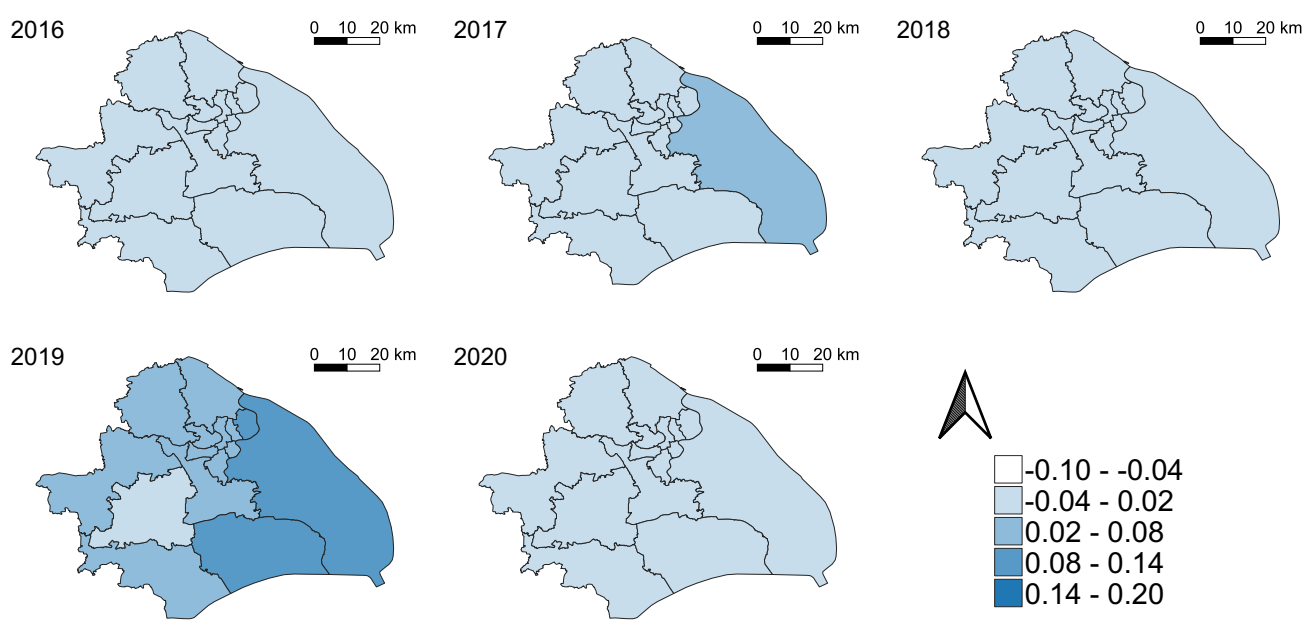

Figure 12. Average value of Wetness in each district.
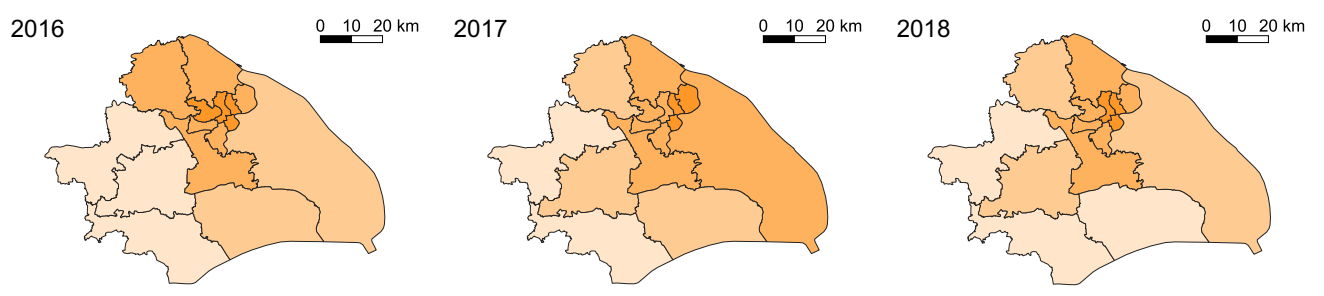

Figure 13. Cont. 


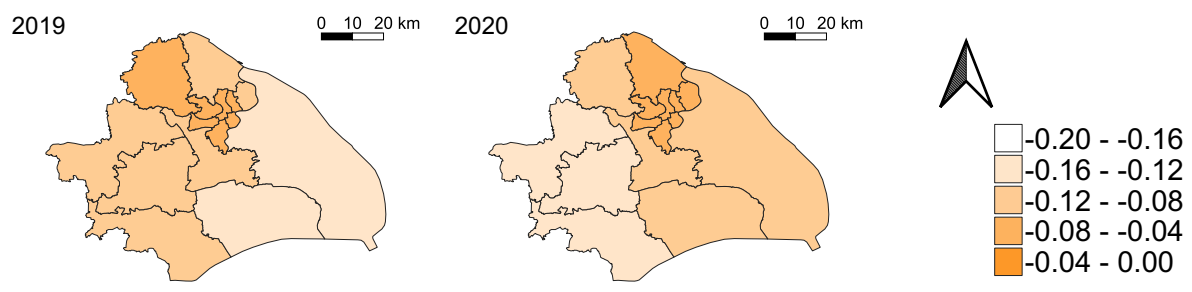

Figure 13. Average value of Dryness in each district.
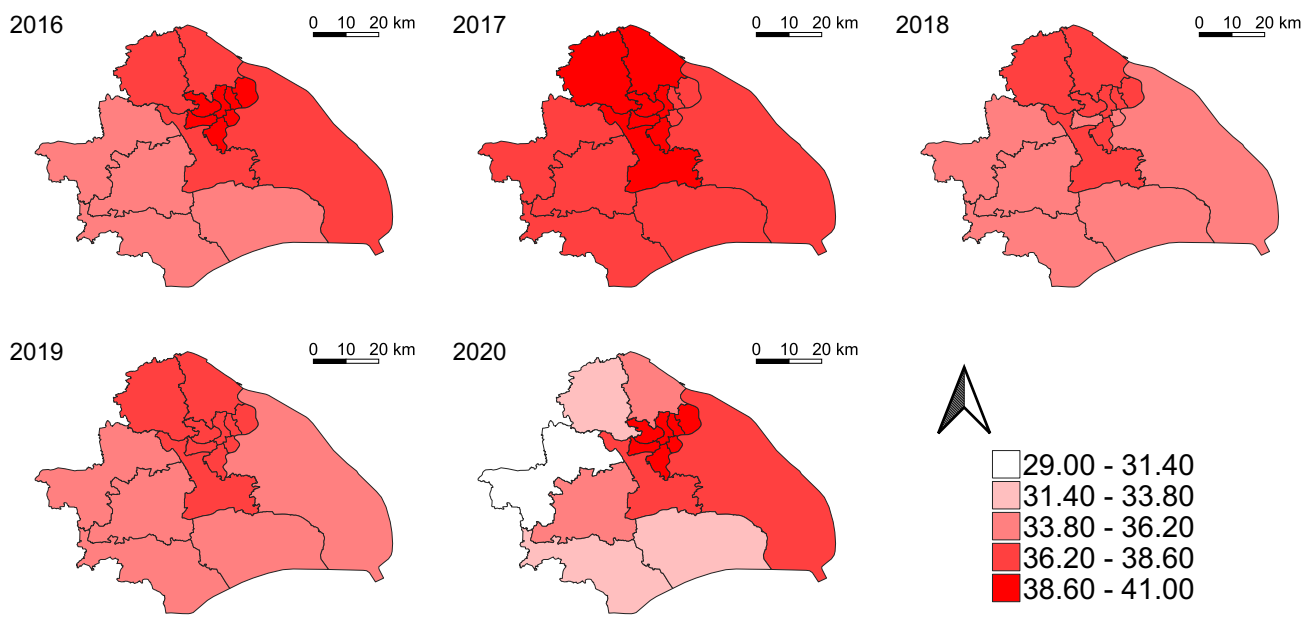

Figure 14. Average value of Heat in each district.

\subsection{Normalization}

Table 4 reports the descriptive statistics for all ecological criteria. From Table 4, it can be seen that the mean value of each criterion varies considerably. Therefore, there is a strong need for normalization. The data are normalized using the method described in Section 2.2, and Table 5 reports the descriptive statistics for data after normalization.

Table 4. Descriptive statistics for ecological criteria.

\begin{tabular}{lcrrrr}
\hline Criterion & Sample Size & Mean & Std. Dev & Minimum & Maximum \\
\hline Greenness & 75 & 0.156 & 0.097 & 0.008 & 0.375 \\
Wetness & 75 & 0.002 & 0.033 & -0.04 & 0.115 \\
Dryness & 75 & -0.077 & 0.034 & -0.148 & -0.016 \\
Heat & 75 & 37.065 & 2.188 & 29.298 & 40.528 \\
\hline
\end{tabular}

Table 5. Descriptive statistics for ecological criteria after normalization.

\begin{tabular}{cccccc}
\hline Criterion & Sample Size & Mean & Std. Dev & Minimum & Maximum \\
\hline Greenness & 75 & 0.403 & 0.265 & 0.000 & 1.000 \\
Wetness & 75 & 0.269 & 0.214 & 0.000 & 1.000 \\
Dryness & 75 & 0.461 & 0.258 & 0.000 & 1.000 \\
Heat & 75 & 0.308 & 0.195 & 0.000 & 1.000 \\
\hline
\end{tabular}

\subsection{RSEI}

According to the projection pursuit model described in Figure 3, the optimal direction vector $\hat{\boldsymbol{a}}$ is calculated, and $\hat{\boldsymbol{a}}=[0.5666,0.0800,0.6819,0.4556]$. Then, the comprehensive evaluation value RSEI of ecological criteria can be calculated, and the results are shown in Figure 15. 

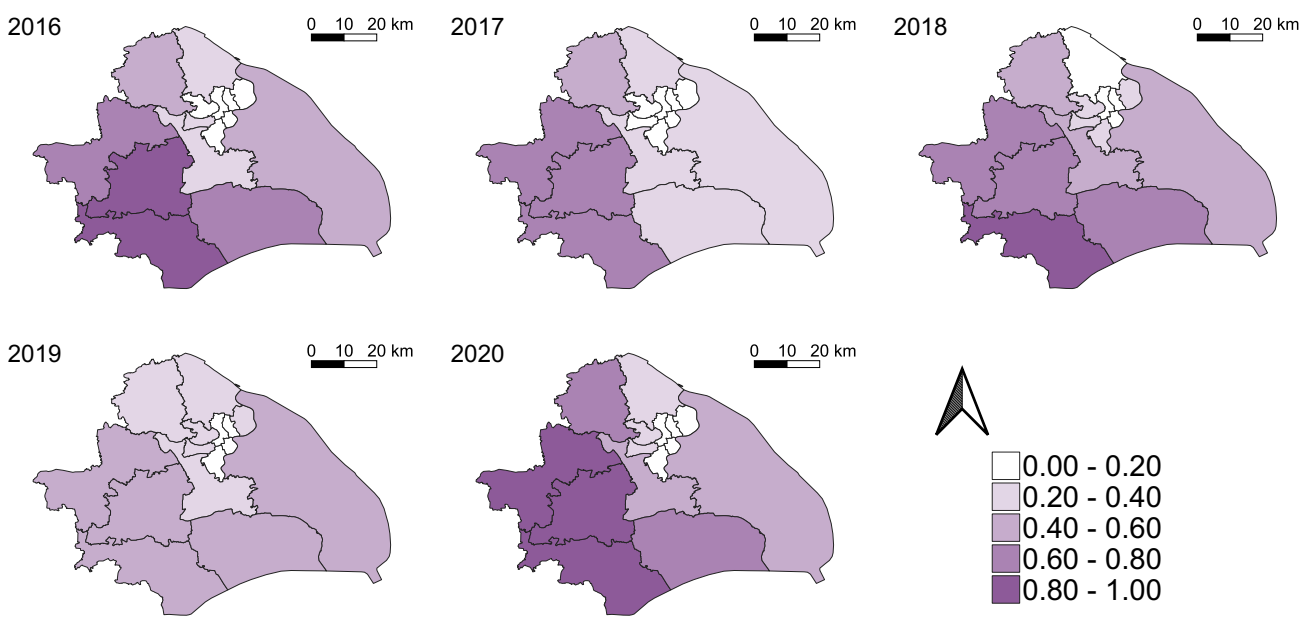

Figure 15. RSEI.

\section{Discussion}

The statistics for RSEI are presented as box plots in Figure 16, and we can see that the average RSEI fluctuated from 2016 to 2020. The average RSEI of Shanghai decreased in 2017 and 2019, but the average RSEI of Shanghai increased in 2018 and 2020. In addition, the average RSEI of Shanghai in 2020 increased obviously compared with that in 2016, indicating that the ecological environment of Shanghai has improved overall.

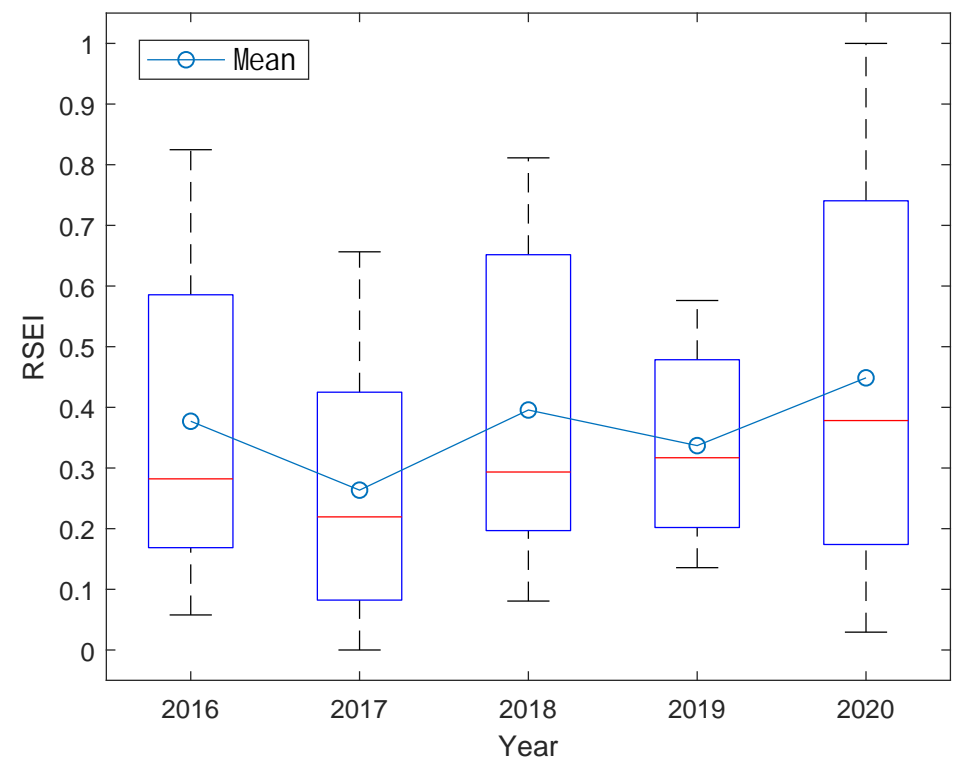

Figure 16. Box plots of RSEI.

Figure 17 shows the changes of RSEI in 15 districts of Shanghai, and we can see that the fluctuation in most districts is similar, but some differences also exist. The RSEI in Jingan District did not change significantly in 2017, while the RSEI in the remaining districts showed an obvious decline. In 2018, the RSEI in Jingan District remained varied slightly, while the RSEI in the remaining districts showed an obvious increase. In 2019, the RSEI in nine districts such as Qingpu showed an obvious decline, while the RSEI in five districts such as Fengxian showed an obvious increase. In addition, the RSEI of Jinshan district changed slightly. In 2020, the RSEI in eight districts such as Qingpu showed an obvious increase, while the RSEI in four districts such as Fengxian showed an obvious decrease, and the RSEI in Jinshan District, Baoshan District, and Xuhui District 
varied a little. However, from the overall perspective, only the RSEI in Huangpu and Yangpu districts did not increase, while the RSEI in the remaining districts all showed an obvious increase, indicating that the ecological environment of most districts in Shanghai improved significantly.

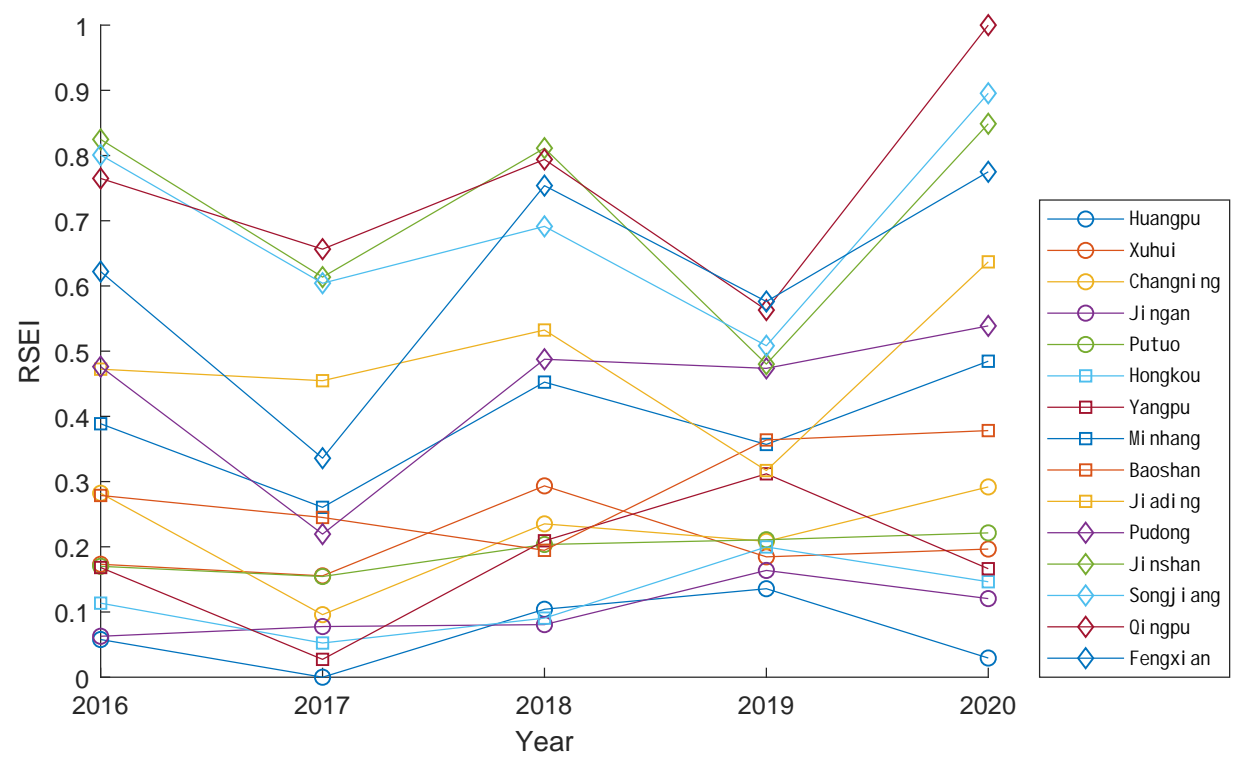

Figure 17. Line chart of RSEI.

In order to compare the ecological environment more conveniently, Figure 18 shows the rankings of each district by RSEI in 2016 and 2020. In 2016, the top three districts were Jinshan District, Songjiang District, and Qingpu District, and the bottom three districts were Hongkou District, Jing'an District, and Huangpu District. In 2020, the top three districts were Qingpu District, Songjiang District, and Jinshan District, and the bottom three districts were Hongkou District, Jingan District, and Huangpu District. It can be seen that whether in 2016 or 2020, Jinshan District, Songjiang District and Qingpu District ranked high in the ecological environment, while there is a lot of room for improvement in the ecological environment of Hongkou District, Jingan District, and Huangpu District. Therefore, Hongkou District, Jingan District, and Huangpu District need to put more effort into enhancing the ecological environment in future.

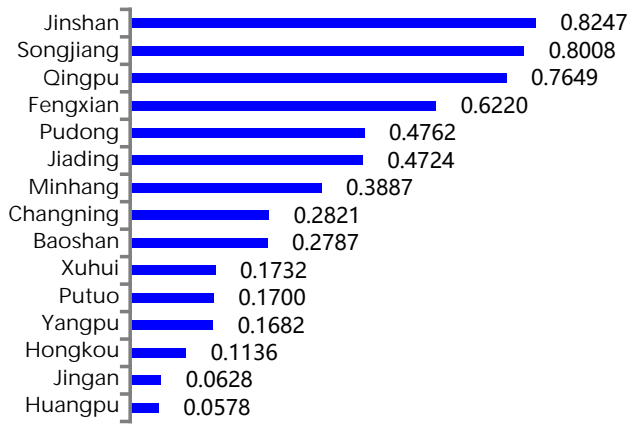

2016

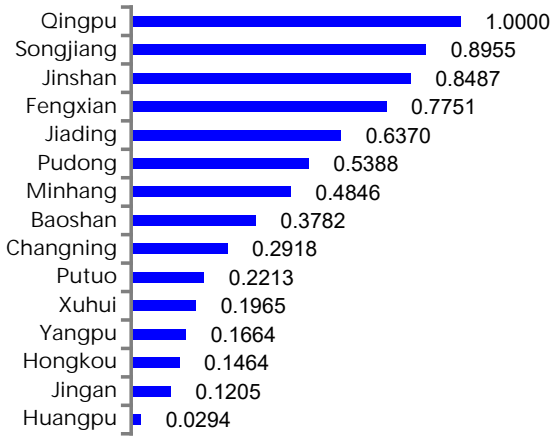

2020

Figure 18. Rankings of each district.

In this paper, we also calculate the RSEI Moran's I for each year. The Moran's I results are shown in Figure 19. 

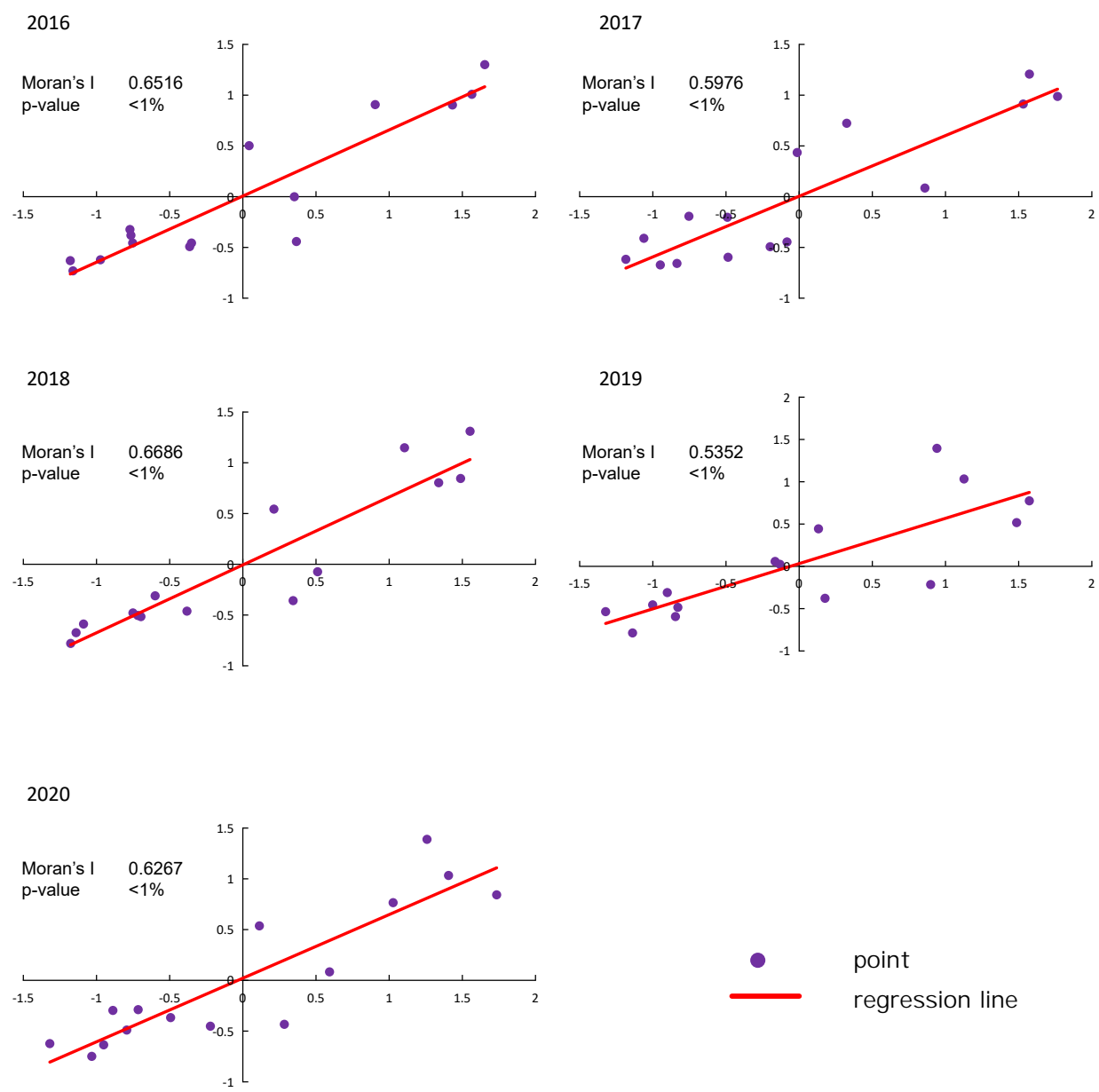

Figure 19. Moran scatter plot.

From Figure 19, it can be seen that the Moran's I values are all positive and the $p$ values less than $1 \%$, indicating that the RSEI has a statistically significant positive spatial autocorrelation. Therefore, when improving the ecological environment, each district should pay attention to the impact of surrounding districts. It is better to cooperate with surrounding districts and develop relevant measures to achieve citywide overall planning.

\section{Conclusions}

The urban ecological environment is one of the most concerning issues at present. In order to evaluate the urban ecological environment more objectively and conveniently, we have carried out the detection based on remote sensing technology, and then proposed a multi-criteria evaluation model to analyze the ecological environment. To begin with, this paper introduces the basic methods for using remote sensing to detect the ecological environment. Then, to make up for the shortcomings of evaluation methods in previous studies, this paper has proposed a multi-criteria evaluation method based on a projection pursuit model. Lastly, the ecological environment changes of Shanghai City in the past five years have been comprehensively evaluated.

This study has found that, in Shanghai (excluding Chongming Island), the average remote sensing ecological index (RSEI) in 2020 increased obviously compared with that in 2016. In addition, Jinshan District, Songjiang District, and Qingpu District have the higher evaluation scores of the ecological environment, while Hongkou District, Jingan District, and Huangpu District have the lower evaluation scores of the ecological environment. In addition, there is significant positive spatial autocorrelation in the ecological environment of all districts. The implications of our findings are as follows.

1. The ecological environment of Shanghai has improved overall in the past five years. 
2. Hongkou District, Jingan District, and Huangpu District should put more effort into improving the ecological environment in the future.

3. The improvement of ecological environment should consider the impact of surrounding districts, and it is better to make an overall plan.

4. The proposed weight setting method is more reasonable, and the proposed evaluation method is convenient and practical.

Future work should focus on the applications of our method in the ecological protection.

Author Contributions: Methodology, Yuxiang Yan; data processing, Yuxiang Yan, Fengyang Long, Yanfeng Dong; funding acquisition, Xianwen Yu; writing - original draft preparation, Yuxiang Yan; writing-review and editing, Xianwen Yu, Fengyang Long, Yanfeng Dong. All authors have read and agreed to the published version of the manuscript.

Funding: This research was funded by the National Natural Science Foundation of China (Grant No. 41974030), and the Postgraduate Research \& Practice Innovation Program of Jiangsu Province (Grant No. KYCX17_0150).

Institutional Review Board Statement: Not applicable.

Informed Consent Statement: Not applicable.

Data Availability Statement: The data can also be available upon request by contact with the corresponding author.

Conflicts of Interest: The authors declare no conflict of interest.

\section{References}

1. Zhang, T.; Yang, R.; Yang, Y.; Li, L.; Chen, L. Assessing the Urban Eco-Environmental Quality by the Remote-Sensing Ecological Index: Application to Tianjin, North China. ISPRS Int. J. -Geo-Inf. 2021, 10, 475. [CrossRef]

2. Hassan, T.; Zhang, J.; Prodhan, F.A.; Pangali Sharma, T.P.; Bashir, B. Surface Urban Heat Islands Dynamics in Response to LULC and Vegetation across South Asia (2000-2019). Remote Sens. 2021, 13, 3177. [CrossRef]

3. Yao, Z.; Xiao, J.; Ma, X. The impact of large-scale afforestation on ecological environment in the Gobi region. Sci. Rep. 2021, 11, 14383. [CrossRef]

4. Shen, Y.; Zhang, C.; Wang, R.; Wang, X.; Cen, S.; Li, Q. Spatial heterogeneity of surface sediment grain size and aeolian activity in the gobi desert region of northwest China. Catena 2020, 188, 104469. [CrossRef]

5. Qureshi, S.; Alavipanah, S.K.; Konyushkova, M.; Mijani, N.; Fathololomi, S.; Firozjaei, M.K.; Homaee, M.; Hamzeh, S.; Kakroodi, A.A. A Remotely Sensed Assessment of Surface Ecological Change over the Gomishan Wetland, Iran. Remote Sens. 2020, 12, 2989. [CrossRef]

6. Xu, H.; Wang, Y.; Guan, H.; Shi, T.; Hu, X. Detecting Ecological Changes with a Remote Sensing Based Ecological Index (RSEI) Produced Time Series and Change Vector Analysis. Remote Sens. 2019, 11, 2345. [CrossRef]

7. Yue, H.; Liu, Y.; Li, Y.; Lu, Y. Eco-Environmental Quality Assessment in China's 35 Major Cities Based On Remote Sensing Ecological Index. IEEE Access 2019, 7, 51295-51311. [CrossRef]

8. Li, Y.; Li, J.; Xu, A.; Feng, Z.; Hu, C.; Zhao, G. Spatial-Temporal Changes and Associated Determinants of Global Heating Degree Days. Int. J. Environ. Res. Public Health 2021, 18, 6186. [CrossRef]

9. Jiang, Y.; Lin, W. A Comparative Analysis of Retrieval Algorithms of Land Surface Temperature from Landsat-8 Data: A Case Study of Shanghai, China. Int. J. Environ. Res. Public Health 2021, 18, 5659. [CrossRef]

10. Zhu, D.; Chen, T.; Zhen, N.; Niu, R. Monitoring the effects of open-pit mining on the eco-environment using a moving window-based remote sensing ecological index. Environ. Sci. Pollut. Res. 2020, 27, 15716-15728. [CrossRef]

11. $\mathrm{Bi}, \mathrm{X}$.; Chang, B.; Hou, F.; Yang, Z.; Fu, Q.; Li, B. Assessment of spatio-temporal variation and driving mechanism of ecological environment quality in the Arid regions of central Asia, Xinjiang. Int. J. Environ. Res. Public Health 2021, 18, 7111. [CrossRef]

12. Zhang, Z.; Zhang, Y.; Yu, X.; Lei, L.; Chen, Y.; Guo, X. Evaluating Natural Ecological Land Change in Function-Oriented Planning Regions Using the National Land Use Survey Data from 2009 to 2018 in China. ISPRS Int. J. -Geo-Inf. 2021, 10, 172. [CrossRef]

13. Peng, T.; Sun, C.; Feng, S.; Zhang, Y.; Fan, F. Temporal and Spatial Variation of Anthropogenic Heat in the Central Urban Area: A Case Study of Guangzhou, China. ISPRS Int. J. -Geo-Inf. 2021, 10, 160. [CrossRef]

14. Firozjaei, M.K.; Fathololoumi, S.; Kiavarz, M.; Biswas, A.; Homaee, M.; Alavipanah, S.K. Land Surface Ecological Status Composition Index (LSESCI): A novel remote sensing-based technique for modeling land surface ecological status. Ecol. Indic. 2021, 123, 107375. [CrossRef]

15. $\mathrm{Hu}, \mathrm{X} . ; \mathrm{Xu}, \mathrm{H}$. A new remote sensing index for assessing the spatial heterogeneity in urban ecological quality: A case from Fuzhou City, China. Ecol. Indic. 2018, 89, 11-21. [CrossRef] 
16. Nie, X.; Hu, Z.; Zhu, Q.; Ruan, M. Research on Temporal and Spatial Resolution and the Driving Forces of Ecological Environment Quality in Coal Mining Areas Considering Topographic Correction. Remote Sens. 2021, 13, 2815. [CrossRef]

17. Wang, Y. Evaluation of lake wetland ecotourism resources based on remote sensing ecological index. Arab. J. Geosci. 2021, 14, 559. [CrossRef]

18. Liu, L.; Huang, J.; Wang, H. Visibility Graph Power Geometric Aggregation Operator and Its Application in Water, Energy and Food Efficiency Evaluation. Int. J. Environ. Res. Public Health 2020, 17, 3891. [CrossRef]

19. Liao, W.; Jiang, W. Evaluation of the Spatiotemporal Variations in the Eco-environmental Quality in China Based on the Remote Sensing Ecological Index. Remote Sens. 2020, 12, 2462. [CrossRef]

20. Wang, Z.; He, X.; Zhang, C.; Xu, J.; Wang, Y. Evaluation of Geological and Ecological Bearing Capacity and Spatial Pattern along Du-Wen Road Based on the Analytic Hierarchy Process (AHP) and the Technique for Order of Preference by Similarity to an Ideal Solution (TOPSIS) Method. ISPRS Int. J. -Geo-Inf. 2020, 9, 237. [CrossRef]

21. Chuvieco, E.; Huete, A. (Eds.) Fundamentals of Satellite Remote Sensing; CRC Press: Boca Raton, FL, USA, 2015.

22. $\mathrm{Xu}, \mathrm{H}$. A remote sensing index for assessment of regional ecological changes. China Environ. Sci. 2013, 33, 889-897.

23. Henrich, V.; Brüser, K. IDB: Index Database. 2021. Available online: https:/ / www.indexdatabase.de (accessed on 8 May 2021).

24. EUMeTrain. Product Tutorial on Land Surface Temperature. 2021. Available online: http://eumetrain.org/data/4/460/ (accessed on 8 May 2021).

25. Kyung Lee, E. Projection Pursuit Methods for Exploratory Supervised Classifcation. Ph.D Thesis, Iowa State University, Ames, IA, USA, 2003.

26. Liu, D.; Liu, C.; Fu, Q.; Li, T.; Khan, M.I.; Cui, S.; Faiz, M.A. Projection pursuit evaluation model of regional surface water environment based on improved chicken swarm optimization algorithm. Water Resour. Manag. 2018, 32, 1325-1342. [CrossRef]

27. Yu, X.; Xie, J.; Jiang, R.; Zuo, G.; Liang, J. Assessment of water resource carrying capacity based on the chicken swarm optimization-projection pursuit model. Arab. J. Geosci. 2020, 13, 13-39. [CrossRef]

28. Xu, Z. Uncertain Multi-Attribute Decision Making; Springer: Heidelberg, Germany, 2015.

29. Xie, L. Advanced Engineering and Technology III: Proceedings of the 3rd Annual Congress on Advanced Engineering and Technology; CRC Press: London, UK, 2017.

30. Anselin, L. GeoDa Workbook. 2021. Available online: http:/ / geodacenter.github.io/documentation.html (accessed on 8 May 2021).

31. Elhorst, J.P. Spatial Econometrics: From Cross-Sectional Data to Spatial Panels; Springer: Heidelberg, Germany, 2015.

32. Zhou, Y. (Ed.) Shanghai Statistical Yearbook; China Statistics Press: Beijing, China, 2020.

33. MATLAB. Image Processing Toolbox User's Guide; The MathWorks Inc.: Natick, MA, USA, 2021. 